Arqueología y Sociedad,

$N^{o} 15,2004$

\title{
La Muralla de Santa*
}

Dr. Julio C. Tello Rojas

Resumen En este artículo, luego de sus diversas exploraciones al Marañón, el Dr. Julio C. Tello presentó las conclusiones de sus trabajos acerca de la Gran Muralla de Santa. Tello sustentó que ésta no era otra cosa que un camino que conectaba la zona costeña con la andina y cuyo carácter era eminentemente religioso y comercial. Asimismo, describió minuciosamente el curso de la Gran Muralla, sus ramales, y las aldeas, ciudades y edificios contiguos a ella. Finalmente, dio cuenta del hallazgo del templo de Ipuna, dedicado al dios Apocatequil.

Palabras clave: Costa Nor-Central, valle de Santa Gran Muralla, Waka Corral, Arquitectura Monumental, Alfareria Muchik.

Abstrac

After several surveys conducted towards the Marañon river, Dr. Julio C. Tello published the results of this research on the Sant Great Wall. Tello stated that this wall was a road that connected the coastal zone with the highlands, and had a religious and economic role. Tello provided a detailed record of the Great Wall course an its branches as well as its adjacent villages, cities and others kinds of building. Finally, he accounted the find of the Ipuna temple dedicated to the Apocatequil god.

Keywords: North Central Coast, Santa valley, Great Wall, Waka Corral, Monumental Architecture, Muchik Pottery.

\footnotetext{
*Este artículo se basa en la revisión que hizo el Sr. Jorge Crovetti del artículo escrito por Julio C. Tello en el diario El Comercio de Lima, el 11 de octubre de 1938, con el título "la Gran Muralla del Norte del Perú". Crovetti presento la revisión al Dr. Tello en un informe fechado el 11 de agosto de 1945, donde además propone incluir un breve anexo que contiene datos de la expedición a la hoya del Marañon de 1934 realizada por Tello y los norteamericanos Richard Cross y Cornelius Van S. Roosevelt. La presente transcripción y selección fotográfica fueron realizadas por Victor Paredes Castro y Wilbert Salas Egusquiza.
} 


\section{XXVI//P5//F1:(1-18)/}

La Muralla de Santa, descubierta en 1931 por los jóvenes aviadores Shippee y Johnson, ha sido uno de los objetivos de mis exploraciones arqueológicas en el norte peruano durante los últimos años. El resultado alcanzado en los diversos viajes que he efectuado con este fin lo doy a conocer aquí sintéticamente. Para ello trato a continuación:

1ro. Del descubrimiento y estudio de la Muralla. 2do. De su recorrido y estructura. 3ro. De la supuesta asociación entre la Muralla y otras estructuras contiguas a ella. 4to. Del propósito de su construcción y de la Nación, Cultura, y Edad a que pertenece. 5to. De la existencia de monumentos similares a éste en otros lugares del Perú.

\section{Descubrimiento y estudio de la muralla}

Los aviadores Shippee y Johnson realizaron, el año 1931, tres viajes aéreos de reconocimiento de la Muralla y, además, uno a pie para examinarla en su extremo occidental. Durante el primer viaje aéreo, efectuado de oriente a occidente del valle, la distinguieron sobre las cimas de los cerros que bordean el río Santa en su parte alta. En el segundo viaje, la siguieron de occidente a oriente, desde la desembocadura del río hasta la sierra por más de 40 millas, perdiéndola de vista a causa de la neblina. En el tercer viaje fotografiaron catorce fuertes, unos circulares y otros rectangulares, que hallaron sobre los cerros a uno y otro lado de la Muralla. Por último, en el viaje a pie, la siguieron por su extremo occidental explorándola ligeramente.

A fines de julio de 1934, realicé un viaje al Alto Marañón y a mi paso por el valle de Santa, acompañado por los jóvenes Richard Cross y Cornelius Van S. Roosevelt, exploré durante varios días la Muralla en su tramo occidental, entre Las Salinas de Guadalupito y el fundo Tanguchi, en una longitud aproximada de $20 \mathrm{~km}$.

En la Expedición Arqueológica al Marañón [de 1937] exploré nuevamente la Muralla en compañía de Toribio Mejía Xesspe, antiguo conservador del Museo de la Universidad, cuya colaboración es muy valiosa dada su vasta experiencia en los trabajos arqueológicos. En esta oportunidad estudié con mayor detalle la Muralla, tracé su exacto curso, levanté los planos de las aldeas, ciudades y edificios principales contiguos a ella y, mediante excavaciones de prueba, logré reconocer la edad y la cultura de los más importantes grupos arqueológicos, junto a los cuales pasa la Muralla, en mi afán por descubrir las posibles asociaciones que pudieran existir entre sí; y por último, logré descubrir el celebrado Templo de Ipuna, dedicado al Dios Apocatequil, de muy alto rango en el antiguo Pantheón peruano.

Los aviadores Shippee y Johnson dejaron constancia documentada e ilustrada de la existencia del monumento sin avanzar explicación alguna fundamentada sobre su propósito o finalidad, sobre la edad y la cultura a la cual pertenece.

Los peruanistas norteamericanos consultados en el año 1932 por American Geographical Society sobre la índole e importancia de la Muralla descubierta, como Kroeber, Seville y Olson, se han limitado, unos discretamente como Kroeber, a remarcar la necesidad de que un arqueólogo competente la examine en el terreno antes de formular juicio sobre ella; y otros a emitir diversas hipótesis de carácter meramente especulativo. Literatos y periodistas extranjeros y nacionales han exaltado posteriormente el descubrimiento de Shippee y Johnson, dando margen a fantásticas teorías y atrevidas especulaciones.

\section{De su recorrido y estructura}

Aún no se ha realizado la completa exploración de la Muralla en todo su largo recorrido. Shippee y Johnson la siguieron a lo largo de la margen derecha del Santa, desde las vecindades de Corongo hasta la ribera del Océano Pacífico. La naturaleza misma de los viajes aéreos de reconocimiento no les permitió conocer las ramificaciones que tiene, las interrupciones que presenta ni los múltiples detalles relacionados con los monumentos y yacimientos arqueológi- 
cos, junto y a través de los cuales pasa, y cuyo conocimiento es imprescindible para la acertada interpretación de su significado. Bajo la impresión sin duda de que ésta Muralla era similar a otras de la antigüedad, como la Gran Muralla del Emperador Adriano que divide en dos la Gran Bretaña, o a la Gran Muralla, que en el siglo III a. C. hizo construir en la China el Emperador CheHwang-Te, los aviadores americanos la consideraron como parte de un sistema de fortificación, un lindero territorial. Creyeron que las estructuras rectangulares y circulares que aparecen sobre las cimas de algunos cerros eran fuertes asociados a la Muralla, sin percibir que estas estructuras no son accesorias de ella desde que aparecen también en las colinas de la otra margen del valle, sino que son acrópolis muy comunes en todo el Perú. Además, como es de suponer, no siendo arqueólogos, no prestaron atención a los múltiples cementerios explotados, salpicados de osamentas blanqueadas por el Sol, junto y a través de los cuales pasa; ni tampoco a los templos donde conducen los diferentes ramales de esta Muralla.

Las exploraciones que yo he realizado en el valle de Santa con el objeto de estudiar este importante monumento han puesto de manifiesto que la Muralla, en su recorrido a lo largo de la margen derecha del río, es simple. Esto es, no presenta restos de ramificaciones en el tramo comprendido entre Tanguchi y Waka Corral. El primero de estos lugares está a $21 \mathrm{~km}$ al oriente de la desembocadura del Santa y el segundo a $10 \mathrm{~km}$. En Waka Corral presenta su primera bifurcación y a partir de este sitio, en su corto trayecto hacia el mar, sus ramificaciones son más frecuentes.

La Muralla en todo su recorrido pasa a través de poblaciones, de cementerios correspondientes a diversos períodos, y de wakas o restos de antiguos adoratorios y templos, monumentos que existen en las hoyadas y flancos de las colinas del valle.

La parte explorada de la Muralla corresponde a tres secciones que fueron recorridas de occidente a oriente: $1^{\mathrm{o}}$ la de los ramales terminales;
2 la comprendida entre la casa del fundo Waka Corral y la casa del fundo Sarcope; y 3 o la comprendida entre Sarcope y las ruinas situadas frente a la casa de la hacienda Tanguchi.

En setiembre del año 1934, acompañado por los jóvenes norteamericanos Roosevelt y Cross, encontré un ramal de la Muralla que corre muy cerca de Las Salinas de la hacienda Guadalupito. A poco menos de medio kilómetro, antes de llegar a la casa de Las Salinas, la Muralla cruza el llano en dirección SO J NE. Ella es aquí relativamente baja, un poco más ancha en la base que en la parte superior: mide $4 \mathrm{~m}$ máximo en la primera y apenas $1 \mathrm{~m}$ en la segunda. Su altura no ha podido determinarse porque en gran parte se halla total o parcialmente desmoronada. Está construida siempre con los materiales que se hallan en las vecindades o más a la mano, ya sea fragmentos de rocas de los peñones contiguos o cantos rodados transportados de la playa marina; siempre pircadas cuidadosamente en sus dos caras y con un relleno de ripio, tierra o basura, esto es, con los materiales extraídos del propio terreno sobre el cual pasa.

A poca distancia de Las Salinas, hacia el mar, la Muralla pasa por un antiguo campamento de pescadores revelado por montones de conchas y basura: conchas pecten quemadas, huesos de llama y ceniza. Este sitio se llama Cabeza de Toro. La Muralla, después de atravesar el llano cubierto de arena, el cual en parte presenta restos de antiguos cultivos por una distancia como de kilómetro y medio de Las Salinas, desaparece como sepultada por la arena en un largo trecho y reaparece más lejos, casi en el límite de la tierra cultivada del fundo Pusal, frente a la isla del Corcovado.

Reconocido y estudiado este tramo de la Muralla volví a Las Salinas y, desde este lugar, continué la exploración del mismo ramal hacia el oriente en su ruta a la Sierra. Para ello tomé el camino de herradura que conduce a Santiago de Chuco y que corre casi paralelamente a aquél desde donde se le puede seguir perfectamente. A menos de medio kilómetro de Las Salinas ascien- 
de por la falda occidental del elevado cerro de pórfido de Waka Corral, que se halla al NE de aquel lugar. La Muralla avanza hasta la mitad de la falda y allí desaparece. La cuesta es muy empinada y el ascenso es dificultoso, no sólo por esta causa, sino porque las partes no inclinadas están cubiertas de una capa gruesa de arena arrastrada por el viento. Se asciende por el camino de herradura de Santiago de Chuco hasta alcanzar una garganta, desde este sitio tuerce hacia el Sur y sigue el curso de la quebrada de Las Brujas que conduce directamente al valle de Santa. Este camino, según refieren los naturales, es muy antiguo. Por él trafican las gentes que bajan de la sierra al valle de Santa, empleando de cuatro a cinco días en el viaje desde Santiago de Chuco a dicho valle.

Descendiendo por esta quebrada, junto al camino y un poco más abajo de la garganta, hay dos rocas aparentemente ferruginosas, de formas extrañas con eminencias y oquedades que tienen el aspecto de metal fundido o de aerolitos. A la percusión producen un sonido metálico y su forma general hace la impresión de porciones desprendidas de un cuerpo mayor. Una de estas piedras simula, muy lejanamente, la silueta de parte del cuerpo de una mujer. Ambas están casi totalmente cubiertas con una multitud de piedras amontonadas por los caminantes que pasan por este sitio. Dichas rocas, según la leyenda popular, son wakas o piedras sagradas donde moran o se hallan encantadas diosas femeninas que, como las brujas, tienen la virtud de tomar formas de diversos animales como búhos, águilas y aún cuadrúpedos alados que vuelan o corren tan velozmente como el venado.

En tiempos muy remotos estas diosas tenían su imperio en las serranías de Santiago de Chuco. Eran las proveedoras de la sal, cuya búsqueda y comercio ha sido siempre uno de los más caros afanes de los indios de la sierra. Ellas lo transportaban desde largas distancias, controlaban su suministro y comercio. Gracias al poder que poseían de encarnarse en animales alados, gozaban del privilegio de ser dueñas únicas del precio- so elemento cuya adquisición era pagada por los indios con sacrificios cruentos y ofrendas de sangre. Cansados los indios de esta tiranía de las diosas buscaron secretamente otros medios menos penosos de conseguir la sal. Con este fin, trataron de descubrir de donde la sacaban sus proveedoras; disfrazándose de gente muy pobre, recorrieron el país mendigando sal y alimentos. De esta forma pudieron saber que en la costa otras diosas más benévolas poseían ingentes riquezas de este mineral. Desde entonces, los indios de Santiago de Chuco se socorrían de allí, muy secretamente, librándose de antiguos sacrificios.

Como era de esperar, el hallazgo produjo un cambio de actitud en las gentes hacia las diosas serranas de la sal. Todas las ceremonias destinadas al culto de ellas se debilitaron; los cruentos sacrificios fueron cada vez más raros. Esto las alarmó y las obligó a espiar a los indios en sus viajes, descubriendo muy pronto que ellos extraían de Las Salinas grandes cantidades del precioso elemento a cambio de alimentos como carne de llama, papa, oca, chochoca y que ofrendaban a sus dueñas que eran también diosas semejantes a aquellas.

Las diosas serranas se empeñaron desde entonces en posesionarse de Las Salinas de Santa, haciendo guerra a muerte a sus legítimas dueñas. Se entabló, por esta causa, una lucha que duró muchos años; algunas veces alcanzaron victorias, en otras fueron vencidas. En una de estas luchas, la más cruel y tal vez la última, las diosas de la costa lograron sorprender a las serranas que se hallaban escondidas en la quebrada. Tomadas prisioneras fueron descuartizadas y sus restos arrojados al aire, los cuales al caer a tierra quedaron petrificados. Dos partes de cuerpo de estas diosas son las piedras meteoritas ya mencionadas.

Desde entonces los indios de Santiago de Chuco obtienen la sal de Las Salinas de Santa amparados por las diosas vencedoras que custodian este precioso elemento. Sin embargo, los indios temen todavía la venganza de las diosas petrificadas; por esto, al pasar por este lugar, y 
con el fin de evitar su desencantamiento o la influencia de sus poderes maléficos, le arrojan piedras para sepultarlas o anularlas. Las ofrendas de piedras frescamente fracturadas, los guijarros y astillas producidas por el rayo, y cargadas por tanto de poder mágico, son arrojadas por los caminantes a los cerros y peñones, a las lagunas y manantiales donde se considera que residen los espíritus maléficos.

La Muralla, que quedó interrumpida en la falda del peñón de Waka Corral, reaparece a trechos sobre las partes más altas del flanco izquierdo de la mencionada quebrada, y corre en línea recta en la misma dirección del eje de ésta hasta unirse con una muralla más grande y mejor conservada que la de Las Salinas, y que está ubicada exactamente a poca distancia del banco norte del valle de Santa. Un reconocimiento cuidadoso de esta muralla grande permitió asegurarme que era la muralla principal, la descubierta por Shippee y Johnson, la que no se alejaba (como la de Las Salinas) demasiado del valle, sino que corría muy cerca de la tierra cultivada ascendiendo por las colinas que bordean la margen derecha.

Entre Waka Corral y Tanguchi, hasta donde alcanza mi exploración, la Muralla corre casi en línea recta a través de las faldas de las colinas que bordean el lecho del río y a muy corta distancia de éste. Atraviesa los llanos o pampas de arena contiguos a la playa, las mesetas altas y los blancos de aluvión que bordean el valle; asciende a la cima

/F4/2a/ Parte de un antiguo sistema de irrigación, muy cerca del lugar donde la Gran Muralla colinda con el mar.

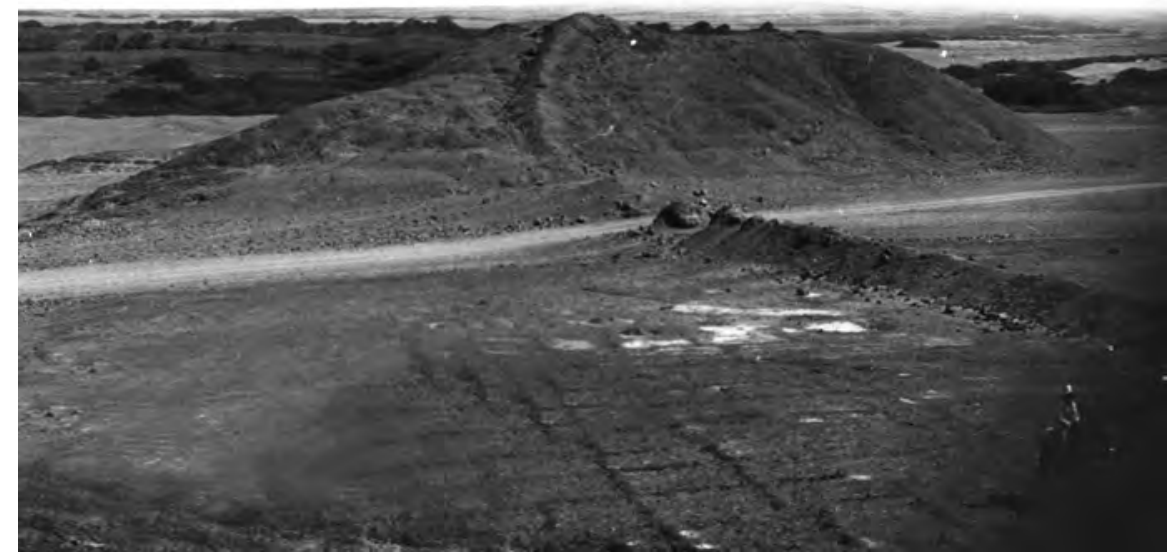

/F4/1a/ (Lugar donde la Gran Muralla empieza su ascenso a las montañas. Véase el mar en la parte superior de la fotografía).

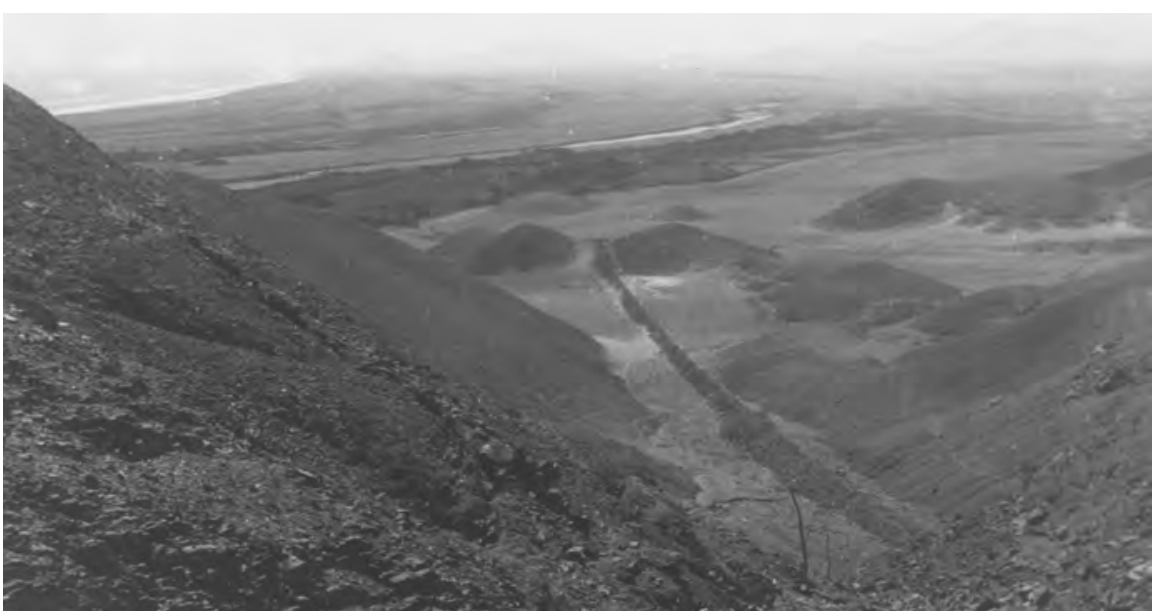


de las lomas y cruza en partes, zigzagueando, las faldas de los cerros, subiendo y bajando por las eminencias y depresiones del terreno, evitando en lo posible los rodeos y desarrollos, o bien, situándose paralelamente al lecho de las pequeñas quebradas como para evitar su desmoronamiento por acción de los derrumbes que, de tiempo en tiempo, se suceden en estas regiones. En los sitios en que el terreno es muy accidentado se desvía de su recta dirección y donde tropieza con pendientes muy empinadas o rocas cortadas a pique, como algunas que se hallan en los bancos de río, se dobla para ascender en línea quebrada hasta dominar la altura. Tal sucede en una sección de la Muralla que se halla a menos de $1 \mathrm{~km}$ al oriente de la casa de Waka Corral. Por regla general, el muro no sigue el fondo de las muchas quebradas secas que encuentra en su recorrido, ni asciende a las cumbres de las colinas muy elevadas; se mantiene siempre en los flancos de los cerros contiguos a la quebrada, atravesando en línea recta las ondulaciones del terreno.

La continuidad de la Muralla se manifiesta en toda su longitud. Sin embargo, en las partes más altas parece que desapareciera pero fácilmente se descubre que sus escombros están confundidos con las formaciones del terreno natural, y muchas de las piedras que la formaban han descendido al fondo de las quebradas vecinas. Las piedras, de un modo general, son mucho

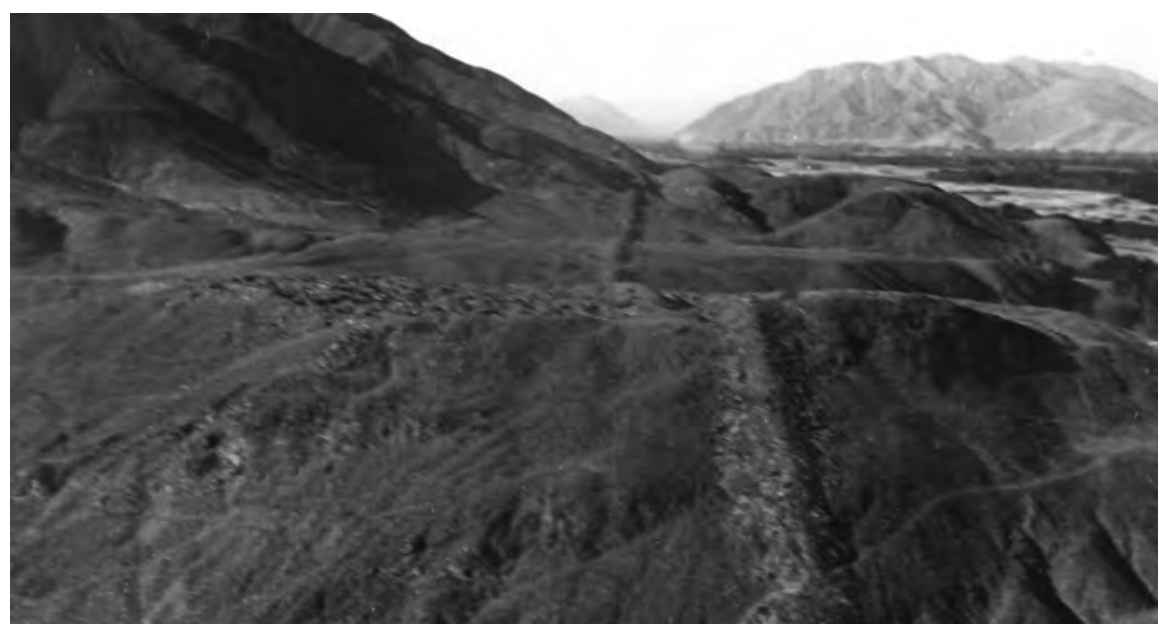

/F4/3a/ Vista panorámica de la Muralla de Santa atravesando las faldas de los cerros.

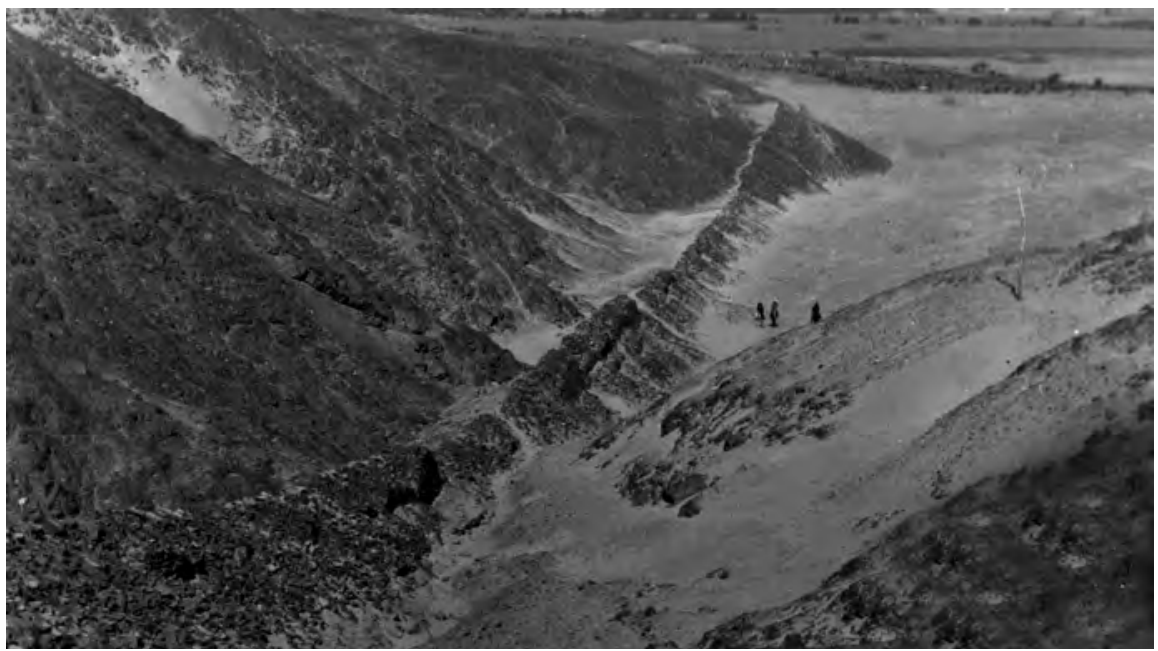

/F4/3b/ En este punto la Gran Muralla asciende por la colina de los cerros. Hacia el fondo se puede apreciar que la Muralla viene del mar. 


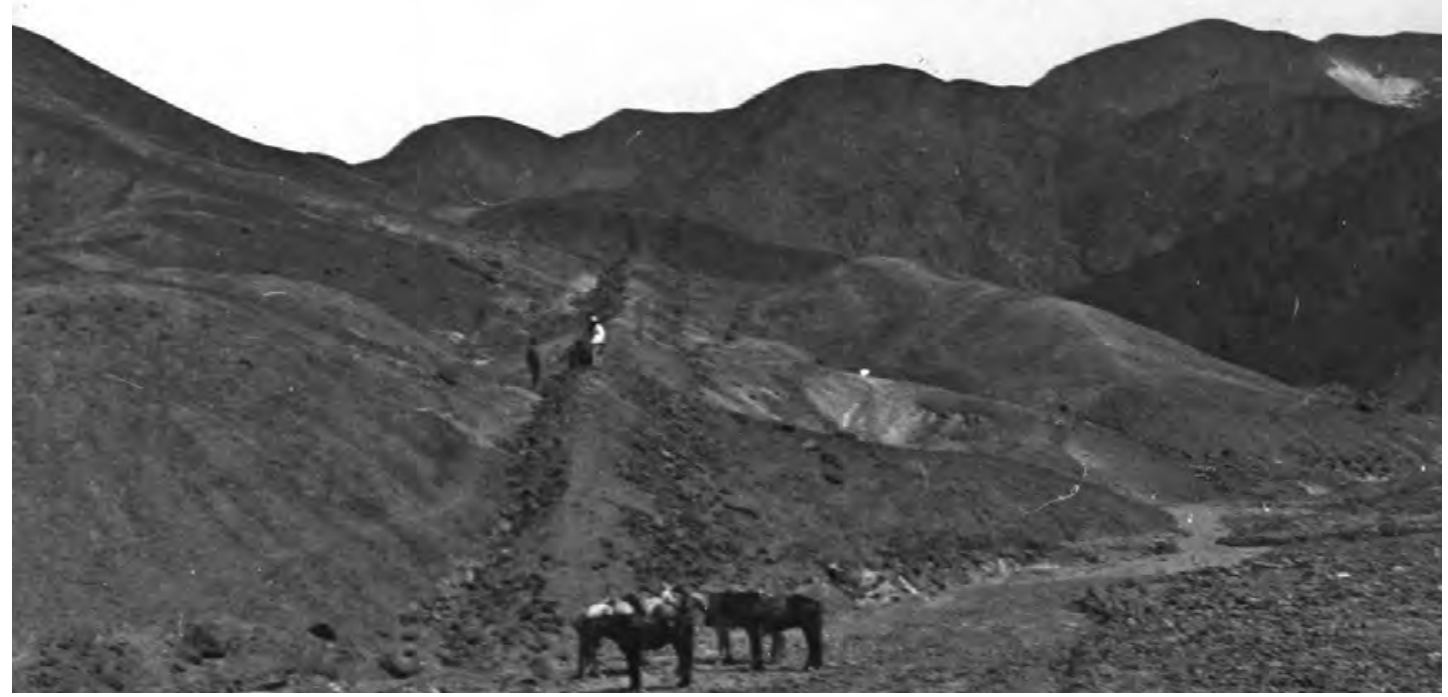

/F4/4a/ Lugar donde se encontró la Gran Muralla por primera vez.

más pequeñas en las partes altas que en las bajas. En casi todas las quebradas del trayecto recorrido, el muro ha sido destruido por las avenidas, principalmente la de 1925, la cual ha barrido la Muralla en porciones considerables y, junto con ella, ha cargado con los basurales y cementerios gentilicios situados en sus vecindades y en las partes bajas. En algunas quebradas entre Waka Corral y Sarcope quedan todavía, en sus flancos, los muros frescamente cortados por las avenidas que han arrastrado todo el material acumulado en el fondo de ellas.

La parte más interesante de mi exploración es el tramo comprendido entre Waka Corral y la ribera del Océano Pacífico. Al pie oriental del cerro Waka Corral y muy cerca del banco de río, la Muralla se divide en dos ramos: uno asciende por la falda del cerro, un poco al NO. Siguiendo de cerca el camino antiguo de Santiago de Chuco, se pierde a trechos y aparece nuevamente junto a Las Salinas; continúa por el llano Cabeza de Toro, que es un viejo paradero cubierto de basura; y desaparece cerca de Pusal.

El muro que va al peñón y pasa cerca de Las Salinas mide entre $1.2 \mathrm{~m}$ y $1.5 \mathrm{~m}$ de ancho y su altura no puede ser mayor de $3 \mathrm{~m}$ dado el volumen del desmonte acumulado al pie. Su estruc- tura es relativamente simple: algunas piedras de tamaño regular, las más grandes en la base, angulosas, transportadas de las faldas de los cerros donde hasta ahora existen grandes acumulaciones. Casi todas las piedras han sido colocadas directamente sobre el suelo o sobre la arena, sin cimientos, y no se descubre que haya habido trabajo cuidadoso de mazonería. No son muros construidos como los de las terrazas agrícolas tan comunes en la sierra, en los cuales las piedras están bien adaptadas entre sí y las caras exteriores niveladas, sino son paredes a manera de cercos rústicos, construidos mediante el apilonado en hileras de piedras con un relleno de cascajo y piedra. Esta falta de solidez ha originado el derrumbe casi total de la Muralla, la que sólo se mantiene casi intacta cuando en la tierra baja ha sido construida con adobes rectangulares y adobones. El examen del relleno verificado en varios sitios no pone al descubierto resto alguno de la actividad humana a no ser cenizas, fragmentos de alfarería utilitaria, salpicadas muy escasamente en el terreno.

Elotro ramo es un poco más complicado en sus bifurcaciones. Pasa por dos cimas de las colinas contiguas al valle; salta la honda quebrada de Gallinazos, donde seguramente debió existir un 
puente; y alcanza una amplia meseta donde se halla mejor conservada. Aquí tiene una dirección perfectamente rectilínea; su ancho aproximado es de $2.5 \mathrm{~m}$. Junto a ella aparece, en este sector, una pista ancha, amplia, bien nivelada, como si hubiera sido construida recientemente. Al llegar la Muralla a la entrada de Inka Pampa, donde hay un peñón con algunas ruinas de habitaciones, se divide en tres ramales: uno, apenas perceptible, que va a perderse en el terreno de cultivo y a destacarse claramente mucho más lejos, en la falda del cerro que se halla junto al puente moderno de Santa donde está el templo de Ipuna. Los otros dos ramos se dividen, a su vez, en subramales que van francamente hacia el occidente, sobre la cima, el pie y la falda de las colinas, hasta alcanzar, unos la tierra cultivada y las acequias antiguas, $y$ otros, la cima del peñón llamado Entre Cerros. La arena ha ocultado el muro en sus terminaciones occidentales pero se nota que él no ha respetado, en ciertos sitios, la tierra cultivada ni los viejos acueductos, como si su propósito fuera alcanzar, venciendo toda dificultad, su destino que en mi concepto fue, por un lado, el Templo de Ipuna, y por otro, algún otro templo que debe existir sepultado en la isla de Corcovado, porque el muro parece terminar su recorrido en un peñón que puede haber servido de embarcadero de balsas. Casi todas las islas de la costa peruana, principalmente las islas guaneras, contienen restos de templos dedicados al culto de la Luna.

En suma, el trazo de la Muralla, en las secciones exploradas por mí, es casi recto y las desviaciones que presenta se deben a obstáculos insalvables o al obligado alejamiento de los acantilados que bordean el valle. Este trazo se adapta, por su estilo, al de los senderos de las serranías por donde trafican a pie los indios. El trazo de estos senderos, como el de la Muralla, obedece principalmente a la necesidad de acortar las distancias. De allí por qué se mantiene el predominio de la línea recta y se da preferencia al ascenso y descenso, muchas veces casi vertical, en vez de los largos rodeos para cruzar las sierras. Los datos relacionados con el término oriental de la Muralla son todavía muy inciertos y sólo cabe conjeturas y suposiciones sobre la base de las informaciones locales y de los restos de los muros allíexistentes.

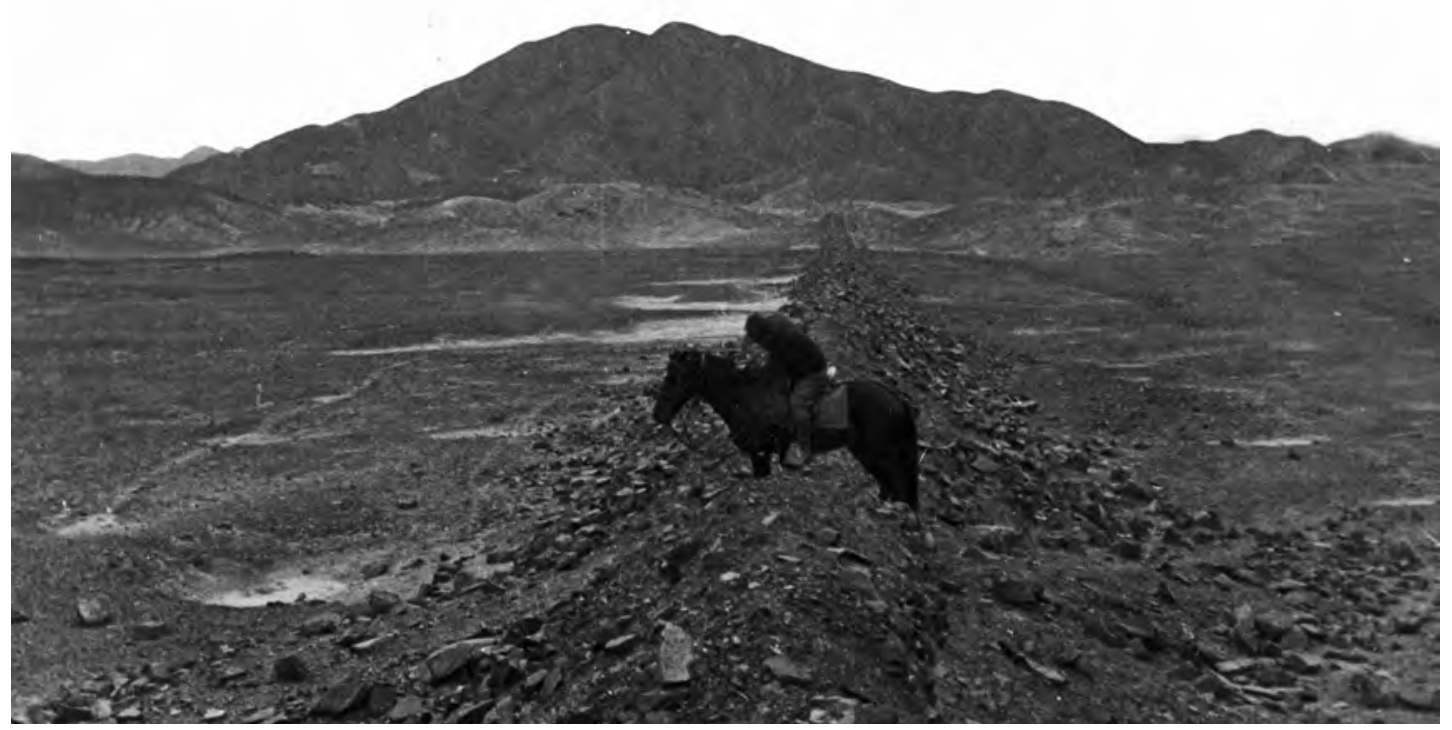

Parte de la gran Muralla cerca de Gallinazo. 
Los aviadores americanos distinguieron la Muralla en las vecindades de Corongo. Hasta ahora no ha sido todavía posible seguirla en su recorrido a través de la provincia de Pallasca. Las informaciones suministradas por los nativos sobre el particular, a pesar de ser vagas e inciertas, son lo suficientemente sugestivas como para vislumbrar que la Muralla, al penetrar a las sierras y cruzar las tierras cultivadas, se divide y subdivide como sucede en su término occidental. Desde luego, en su curso por la margen derecha del río Santa, debe necesariamente mantenerse en la altura porque de otra manera no habría sido percibida por los aviadores. La exploración de este tramo permitirá conocer si se conecta con el camino incaico que va en dirección $\mathrm{N}$ - S, entre Pallasca y el Callejón de Huaylas, y que fue el que siguió Hernando Pizarro en su viaje a Pachacamac; osiloatraviesa trepandola cordillera para pasar a la cuenca del Marañón. La Muralla, de acuerdo con las notas de Shippee y Johnson, no aparece en rigor claramente sino en las alturas de La Limeña. Es muy posible que de este lugar parta un nuevo ramo contiguo a la quebrada de Chumllay y que avance por las poblaciones de Llapuy y Tauca hasta alcanzar el afamado Templo de Cabana. Este es el tramo menos problemático que lo menciono sólo a base de informaciones populares. Otro ramo, el más importante, sigue la margen derecha del Tablachaca o Chuquicara, más o menos a lo largo del viejo camino de herradura entre el valle de Santa y Santiago de Chuco. Las informaciones sobre este ramo son más precisas y es probable que la Muralla avance más allá de Santiago de Chuco hasta alcanzar Porcón, donde están las ruinas del celebrado Templode Apocatequil.

Los restos de muros encontrados cerca de Santiago de Chuco, Pallasca, Corongo y Huamachuco pertenecen sin duda a una red mural desprendida del tronco principal del Santa. Se podría imaginar, tal vez, que la Muralla sigue por la margen del río Chuquicara en dirección de Huaylillas, afluente de éste, hasta Santiago de Chuco; o bien puede avanzar a la hacienda Angasmarca y por aquí continuar por la quebrada de Quishguayhuar, penetrar a la Pampa de Yamobamba, donde existen restos claros de la Muralla, y avanzar hasta Marka Huamachuco. Por último, puede haber seguido el río Tablachaca, penetrar por la quebrada de Piscochaca hasta encontrar el muro cerca de Corongo y alcanzar el cerro Huaylillas, la Laguna Negra y el Cerro Sasón, lugares donde aparece otra vez la Muralla. Por último, restos de otro ramal aparecen en la margen izquierda del Santa entre, La Limeña y Pachmar, y continúa hasta alcanzar Corongo.

El material empleado en la construcción de la Muralla es el que se halla más accesible en los sitios por donde pasa: trozos pequeños de rocas fragmentadas por la acción de los cambios de temperatura, cantos rodados, grava, barro, y aún basura para los rellenos.

En las partes bajas y llanas, cerca del Océano Pacífico, la Muralla está construida con adobes rectangulares y en algunos sitios con un cimiento de piedras rodadas. En el extenso llano de Inka Pampa contiene piedras cargadas de las colinas contiguas y adobes rectangulares hechos con tierra sacada de los terrenos de cultivo.

En las partes más elevadas y sobre las faldas empinadas y cima de las colinas hay un predominio de piedras pequeñas que al desmoronarse han sido, en parte, arrastradas por las lluvias y el mortero de barro eliminado por el viento. De un modo general, la Muralla es muy delgada en las partes altas y aumenta de grosor y altura a medida que desciende alllano.

La técnica de la construcción es semejante a la empleada por los indios en trabajo de mampostería, andenes agrícolas, andenes viales, calzadas y cercos. Los lienzos de sostenimientos son de piedras apilonadas, barro, cascajo y basura. Ciertos rezagos de torta hallados en las caras del muro permiten suponer que, por lo menos en parte, ha estado tarrajeado y enlucido. Los temblores, las fuertes lluvias y las corrientes aéreas han hecho colapsar los muros en algunos sitios hasta subase. 


\section{De la supuesta asociación de la Muralla con otras estructuras contiguas a ella.}

En su recorrido, la Muralla pasa al lado o a través de ruinas de poblaciones y paraderos, de cementerios y muy distante de las pukaras o acrópolis construidas sobre los cerros que bordean el valle por ambos lados. El ramal de Las Salinas pasa por un antiguo paradero de pescadores llamado hoy Cabeza de Toro cuya vasta área está indicada por residuos de cocina, huesos de animales marinos y llama, y fragmentos de alfarería rústica. Sobre estos restos se destacan montones de piedras rodadas, sin duda cimientos de viviendas, algunos batanes y fragmentos de morteros y aún restos de origen postcolombino.

En el tope y falda del Cerro Ipuna, la Muralla, por su estilo, recuerda a la que circunda y asciende en caracol el peñón de Chimú Capac en Supe y que tiene de lejos la apariencia de una fortaleza. Pasa también junto a las ruinas de poblaciones de diferente extensión. Algunas son grupos de posadas modestas; otras parecen corresponder a residencias de curacas por la circunstancia de estar ubicadas sobre subestructuras tronco cónicas. En Inka Pampa, la Muralla tiene un pequeño ramal que conduce directamente a un templo que debió tener cierta importancia porque algunas de sus habitaciones están adornadas con frescos policromos de estilo Muchik.

A la entrada de la quebrada de Gallinazos, contigua a la tierra cultivada y a muy corta distancia de la Muralla, se hallan las ruinas de un templo incaico. El estilo de las construcciones, los pequeños nichos trapezoidales de las paredes, los depósitos destinados al almacenamiento de vitualla y el estilo de la alfarería hallada en fragmentos en la basura constituyen un conjunto de elementos culturales característicos de la cultura incaica. Esta clase de establecimientos se encuentran en casi todos los valles de la costa y corresponden al asiento o residencia de los colonos, gobernadores o administradores incaicos, encargados especialmente a la recaudación de los tributos.
Frente a la casa hacienda de Vinzos y sobre una extensa formación rocosa contigua al lecho del río Santa, se encuentran las ruinas de una interesante población: la de Sarcope. Todas las habitaciones son de piedra; muchas de las paredes están todavía en buen estado; al pie de la población hay un montículo artificial de $5 \mathrm{~m}$ de alto y con terrazas escalonadas. En la parte superior del montículo hay numerosos restos de alfarería ordinaria.

La Muralla atraviesa la población, dividiéndola en dos mitades, sin que exista el más insignificante vestigio de relación entre ambas, como si hubiera estado abandonada cuando aquella fue construida. Restos de viviendas arruinadas se hallan también en El Cenicero, que es una antigua fábrica de alfarería Muchik, y que se encuentra entre Sarcope y Tanguchi. Se ve aquí las ruinas de una población de alfareros, un cementerio y gruesas capas de basura que atestiguan una larga ocupación. Las lluvias torrenciales del año 1925 han cortado estas capas hasta una profundidad, en ciertos sitios, de $3.5 \mathrm{~m}$ poniendo a la vista multitud de fragmentos de alfarería, tanto ceremonial como utilitaria.

A la entrada del Río Seco, muy cerca de Tanguchi, se ve igualmente los restos de una población o tambo al pie de un cerro de pendiente muy fuerte que forma el flanco de la quebrada por el lado occidental. Aquí hay dos grandes y altas murallas como de 9 m de alto: una de ellas orientada de $\mathrm{S}$ - N, en dirección al eje de la quebrada, y otra de $\mathrm{E}$ - $\mathrm{O}$, dirigida hacia las pendientes del cerro y perpendicular a la primera. Tal vez ellas sean restos de una muralla rectangular que encerraba o defendía una pequeña población a juzgar por las acumulaciones de basura y de cocina existentes en sus inmediaciones.

Más hacia el oriente de la quebrada de Río Seco, y contiguo al fundo Tanguchi, existen también ruinas de pequeñas poblaciones dispuestas en terrazas y mesetas naturales. Hileras de piedras amontonadas, formando pequeños rectángulos, y un denso salpicado de fragmentos de alfarería son testimonios de antiguos estable- 
/F4/9p/ El Dr. Tello tomando nota de los detalles de la construcción del gran templo que está detrás de Santa Clara y junto a la Gran Muralla.

/F4/6b/ Fuertes que están a lo largo de la Gran Muralla, muy cerca de Waka

/F4/9q/ Grandes fortificaciones junto a la Gran Muralla cerca de Waka

Corral.
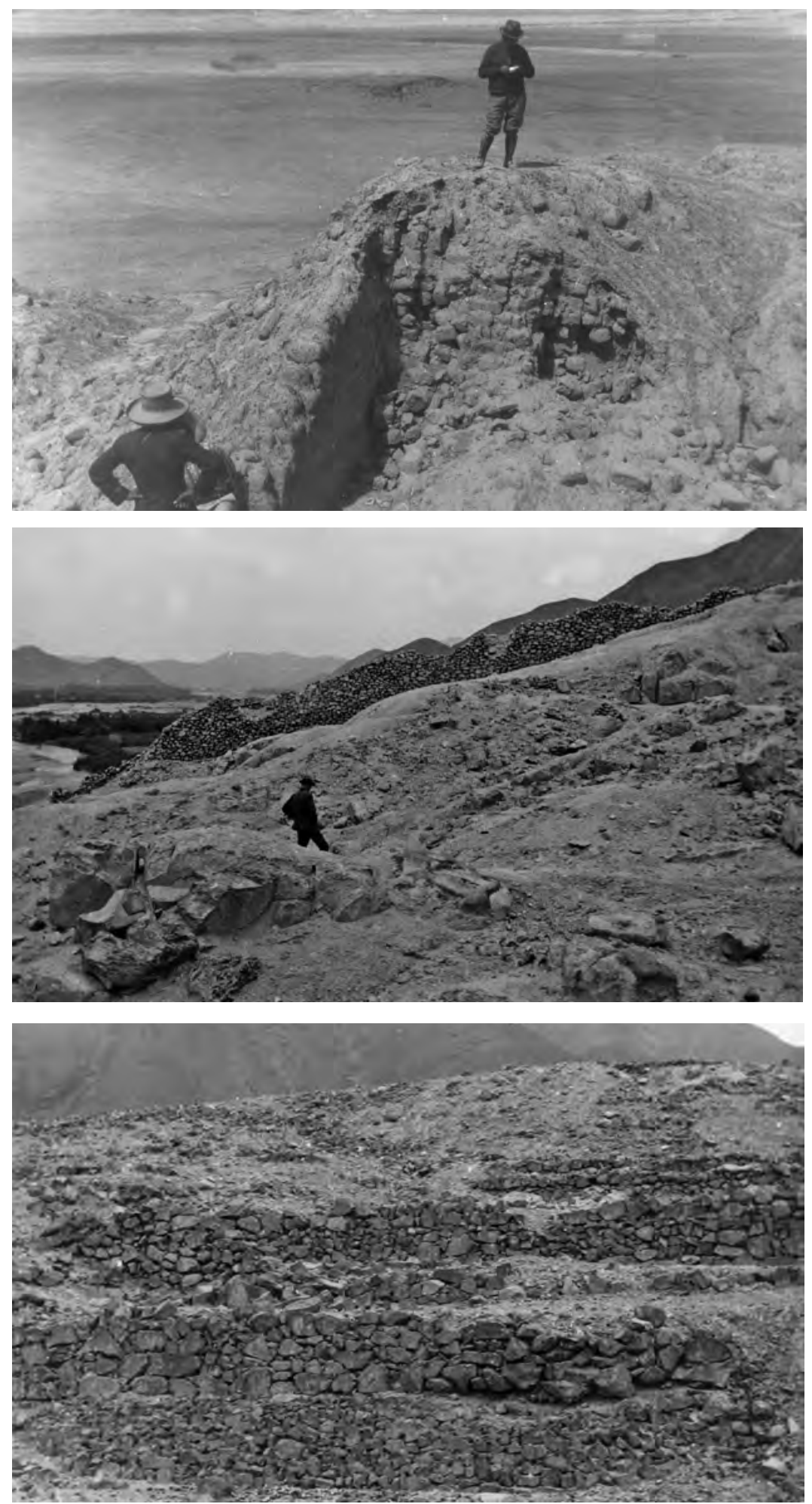
cimientos humanos en estos lugares. La Muralla pasa junto a estas poblaciones, y aún a través de ellas, y a ciertos sitios aproximadamente corre paralela al camino de herradura que conduce a Santiago de Chuco.

Son muchos los cementerios a través de los cuales pasa la Muralla. En El Cenicero, en Tanguchi, en Waka Corral, en Gallinazos y principalmente en Inka Pampa, los wakeros han explotado tumbas que se encuentran muy cerca o debajo de los cimientos de muro. En uno de estos cementerios, como el que se halla entre Sarcope y El Cenicero, comprobé la existencia de dos tumbas superpuestas correspondientes a dos periodos: la inferior contenía un cadáver con fragmentos de alfarería del tipo arcaico de Huaylas y la superior contenía cadáveres relativamente recientes con alfarería de tipo Muchik.

No existen, en rigor, como se ve, testimonios que permitan establecer una clara asociación entre los cementerios, las pequeñas aldeas, los templos, adoratorios y otras estructuras de diferentes épocas, y la Muralla. Pero puedo afirmar categóricamente que los ramos terminales de la Muralla conducen, casi todos ellos, a las cimas de los peñones que dan al mar en donde hay estructuras aparentemente de carácter religioso y cementerios en sus contornos.
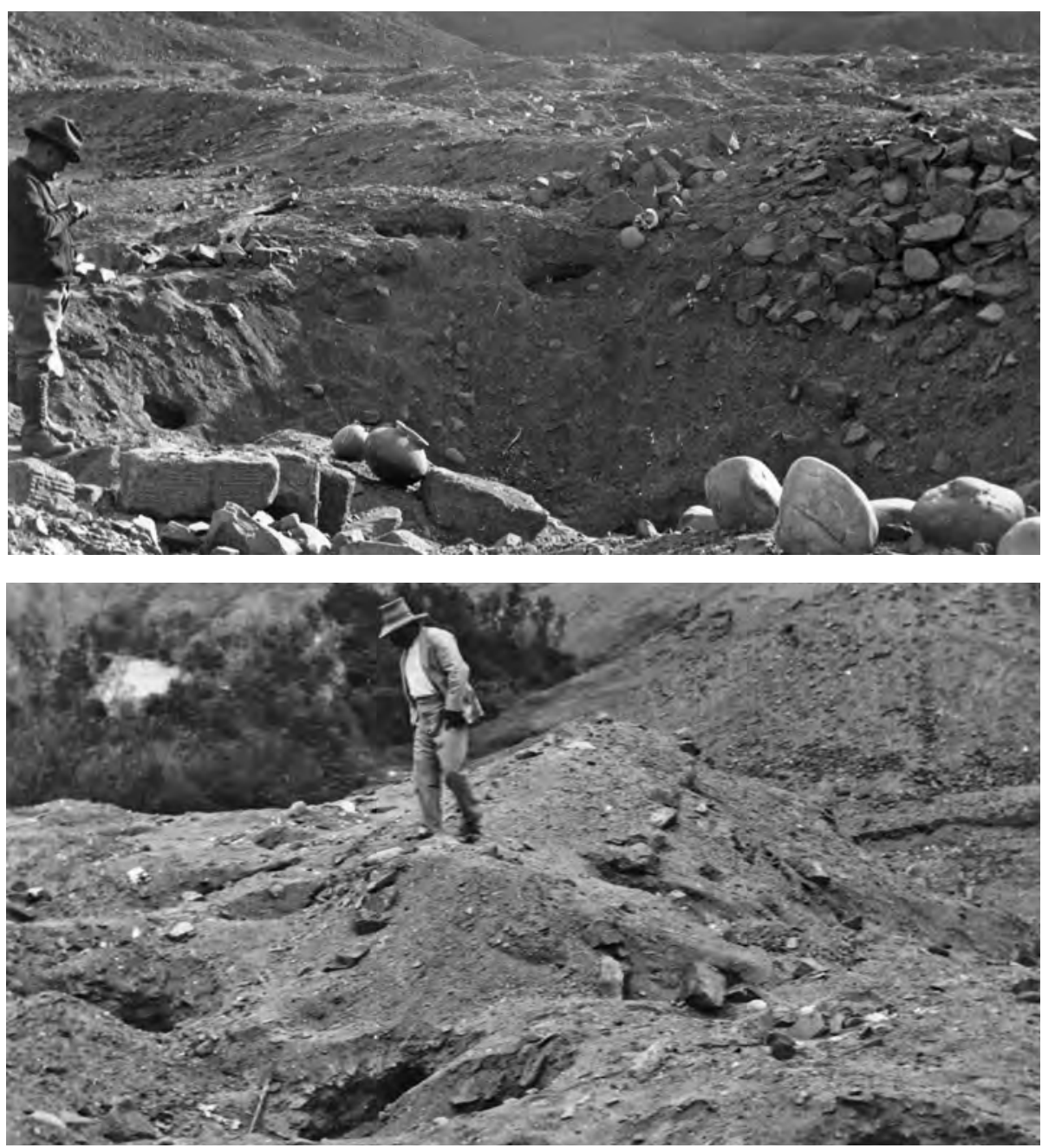

/F4/8a/

Cementerio

cercano a la Gran Muralla, muy cerca de Waka Corral. El Dr. Tello tomando notas.

/F4/8b/ En esta vista, la Gran Muralla atraviesa, por encima, un cementerio. 
Del propósito de su construcción y de la nación, cultura y edad a que pertenece.

La existencia de una muralla tan extensa como la de Santa, que parte de la ribera del Océano Pacífico, asciende directamente hacia la Sierra y avanza con toda probabilidad hasta sobrepasar la Cordillera Occidental, da margen a muchas suposiciones cuando se pretende indagar acerca de su origen y fines a que fue destinada.

Dos son las principales hipótesis hasta ahora planteadas: $1^{\mathrm{a}}$. - La de una muralla de defensa o de un sistema de fortificación, según pensaron sus descubridores Shippee y Johnson; y 2a․- La de un lindero territorial, tal como lo suponía el eminente y ya finado americanista Marshall $\mathrm{H}$. Saville.

A estas hipótesis yo me permito, basado en mis estudios en el terreno, plantear la siguiente tesis: La Muralla de Santa es un camino de pene- tración que atraviesa el país de occidente a oriente y que representa uno de los tantos elementos del vasto y admirable sistema vial de los antiguos peruanos.

Cuando los aviadores descubrieron la Muralla lo que más les impresionó fue la presencia, sobre las cimas de las colinas contiguas a ella, de estructuras circulares y cuadrangulares que parecían fuertes. Desde el avión les fue difícil disociar estos dos elementos arqueológicos. No existe entre ellos, como lo he dicho antes, relación alguna de contigüidad o contemporaneidad. Los supuestos fuertes son acrópolis que existen desparramadas por todo el territorio del Perú y que los españoles llamaron indistintamente castillos, fortalezas, huacas y que, en rigor, no son otra cosa que pequeños templos o adoratorios. Ninguno de estos fuertes podría dar cabida a mas de cincuenta personas y muchos de ellos

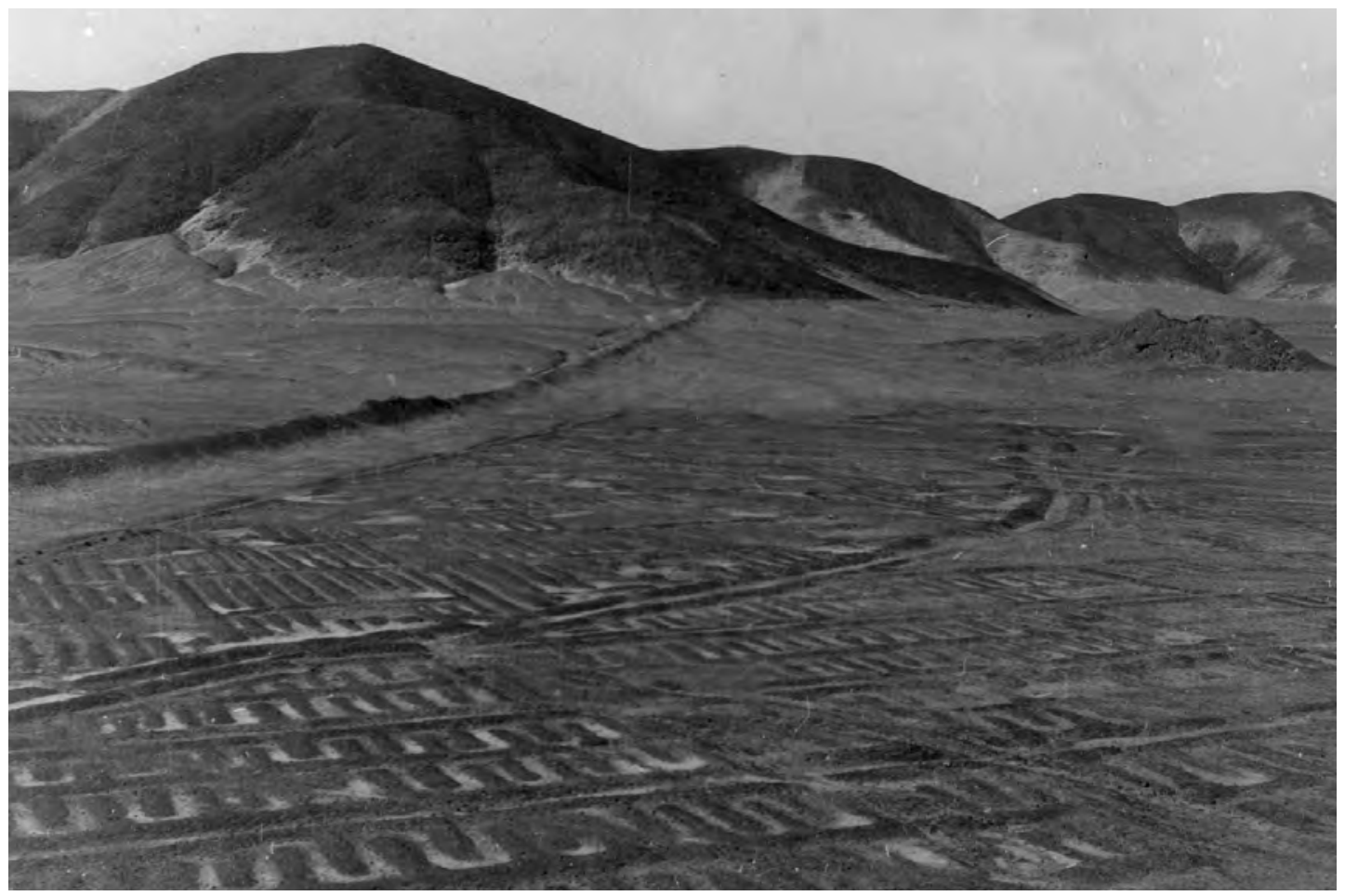

/F4/10b/ Antiguo sistema de irrigación sobre el valle, detrás de Santa Clara. El gran templo se encuentra al fondo, mientras el muro corre a través de la fotografía. También se ve una zanja paralela que da la apariencia de una carretera. 
están situados en lugares de difícil acceso y carentes de los medios indispensables de vida.

Cuando un pueblo edifica una muralla de fortificación lo hace impulsado por un espíritu de defensa, por el interés de salvaguardar su patrimonio territorial del asedio de otra nación enemiga. Por consiguiente, la barrera levantada para este fin tiene que llenar ciertos requisitos que aseguren este propósito. La fortificación tiene que ser lo suficientemente sólida para evitar que el enemigo la destruya, la asalte o la socave con facilidad. Tiene que ser suficientemente alta para no ser escalada y contar con elementos accesorios como parapetos, escalas, entradas fortificadas y atalayas.

La Muralla de Santa no satisface el propósito de una fortificación. Lejos de hallarse edificada a lo largo de los lugares más encumbrados para dominar al enemigo desde la altura se halla, por el contrario, casi en toda su longitud, en las faldas y partes más bajas de las colinas y en muchos sitios al nivel del llano, penetrando aún en el cauce del río. En el llano, su altura no es suficientemente apropiada para una defensa. A juzgar por el volumen del material descombrado, su altura no sería nunca mayor a $3 \mathrm{~m}$. En los sitios en que el suelo presenta elevaciones, el muro al pasar sobre ellas se reduce considerablemente y, en ciertos lugares, su altura no debió ser mayor a $1 \mathrm{~m}$. Ninguna de las estructuras contiguas a la Muralla pueden ser consideradas como fuertes.

Aún menos fundamento existe para sostener la tesis de que la Muralla sea un lindero territorial divisorio entre las naciones antiguas de la costa. En su largo recorrido atraviesa, como he dicho ya, tierras cultivadas, cementerios y poblaciones situados en la hoya hidrográfica del Santa. Sería lógico suponer que una cadena de cerros, un río o cualquier accidente natural sirviera como lindero entre una nación y otra, como sucede en las tierras pastales y de cultivo de los ayllus del interior del Perú. Pero parece fuera de toda lógica suponer que una muralla que pasa a través de pueblos, tierras de cultivo y de otros lugares de intensa actividad humana, correspon-

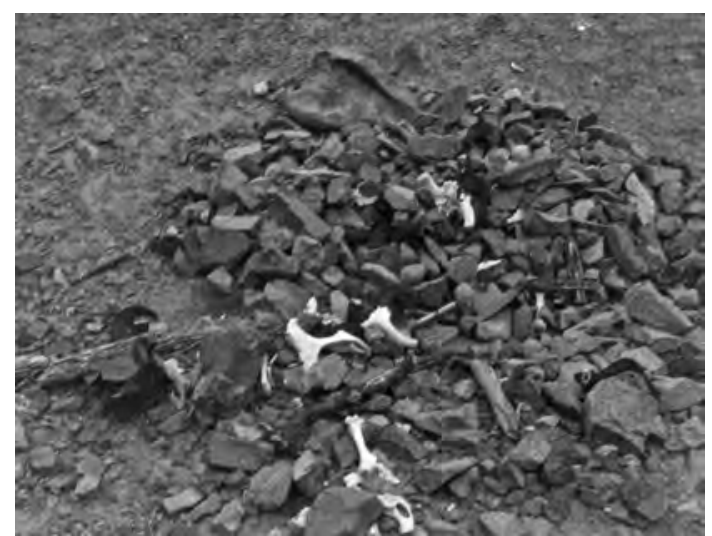

/F4/10a/ Pila de huesos encontrada en un bajo pasadizo en el cerro la Virgen, cerca de Santa Clara. Se supone que han sido brujas convertidas en piedras.

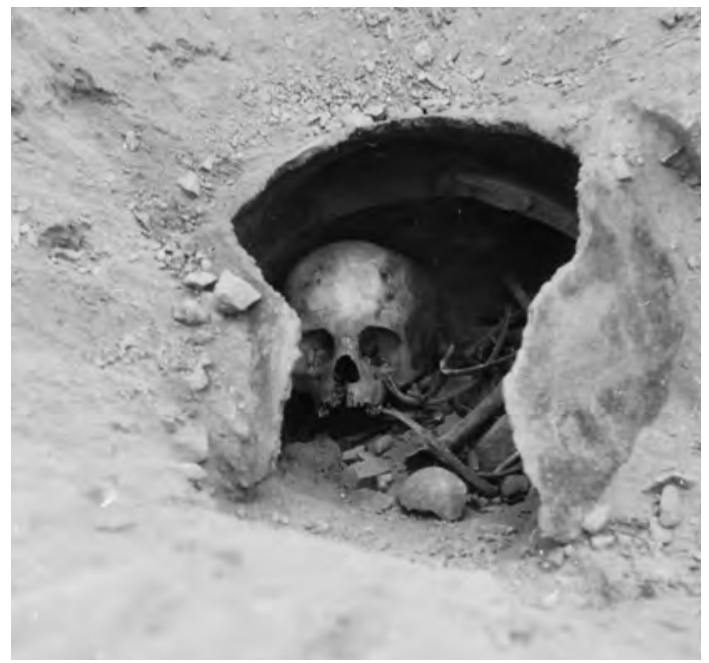

/F4/12b/ Momia de bebé encontrada en el flanco oeste del cementerio en Waka Corral.

diente a la región agrícola de Santa, sirviera como límite territorial de naciones como la Chimú e Inka, por ejemplo.

La Muralla es una línea casi monótona, desnuda, una obra de mazonería que atraviesa sólo en parte terrenos bajos, fértiles o de cultivo. Ella no ofrece, en los muchos kilómetros que la he recorrido paso a paso, atractivo alguno. Siguiéndola por donde pasa es como seguir la línea del telégrafo. Compulsando los múltiples hechos, productos de mi larga y perseverante 


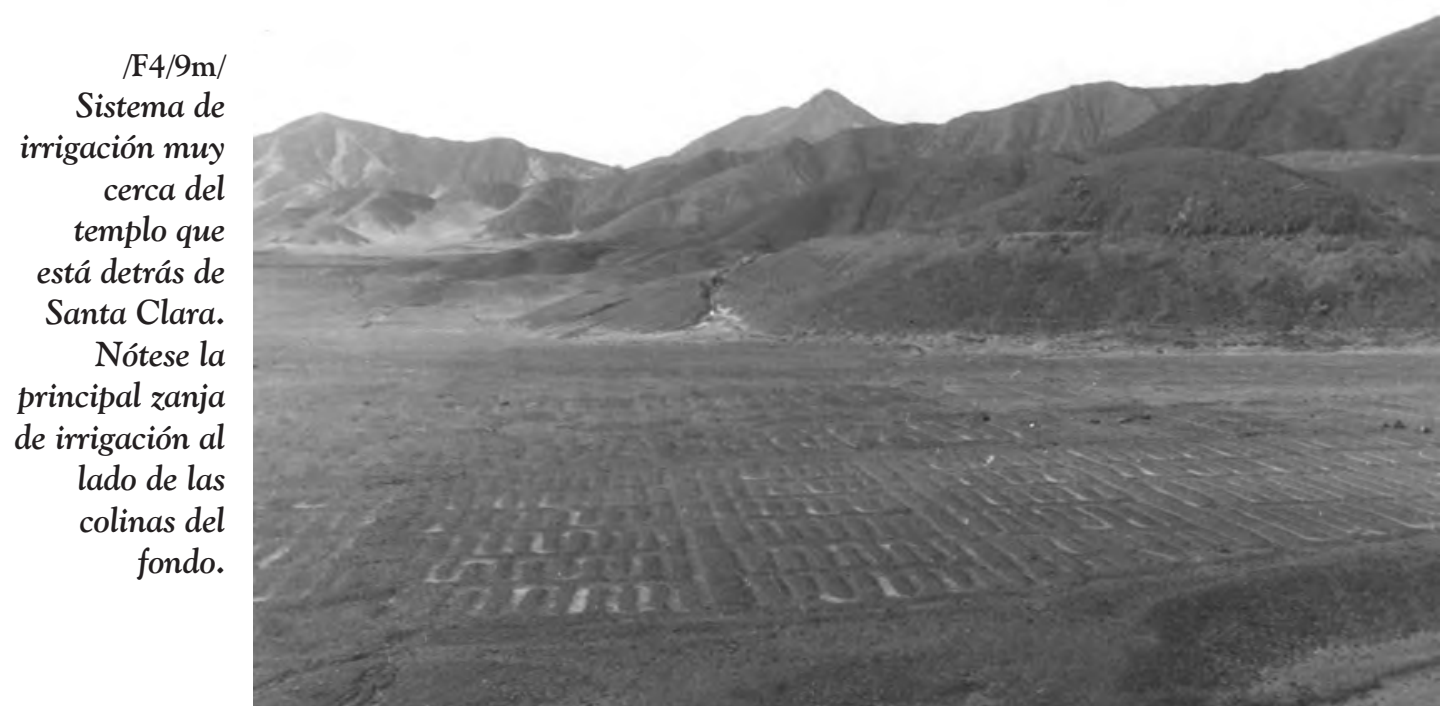

/F4/11b/ Vista donde la Gran Muralla termina en el mar. A la izquierda se aprecia el antiguo sistema de irrigación.

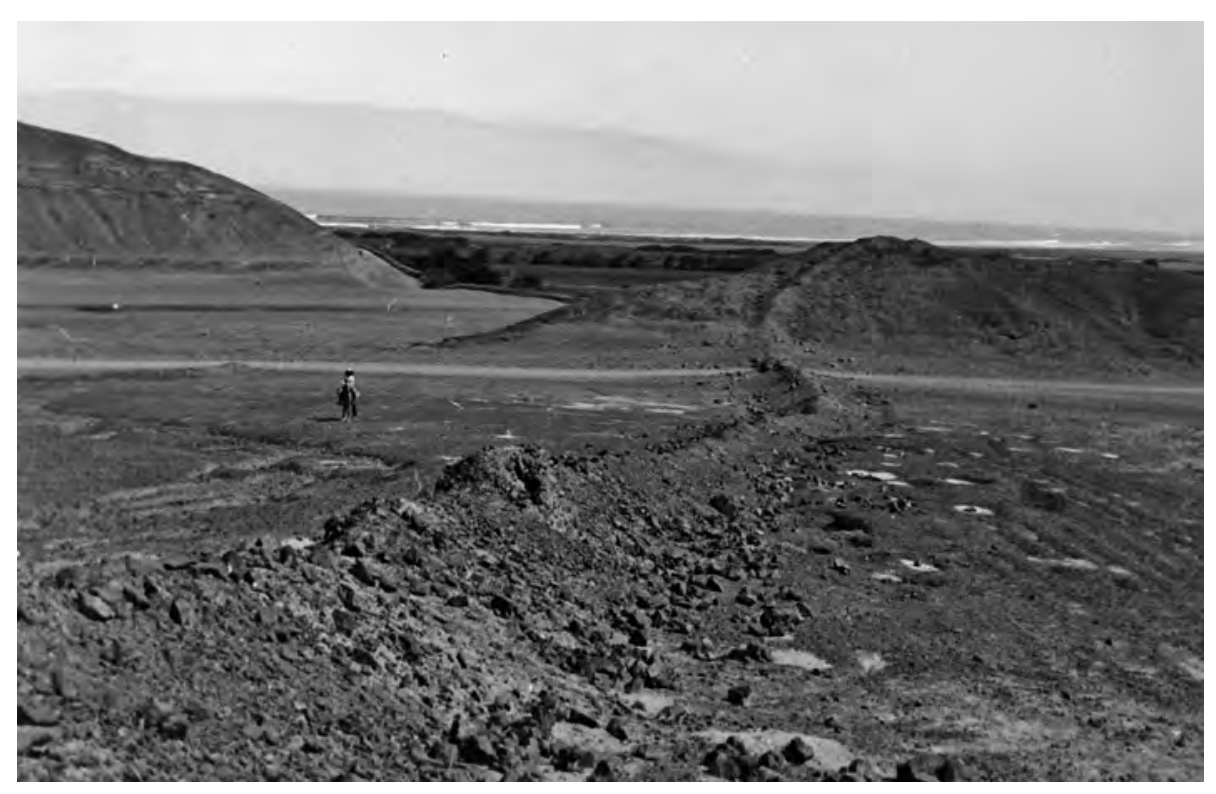

observación, llegó al convencimiento de que la Muralla no es otra cosa que un camino: unas veces se camina sobre el muro y otras veces a su lado, como si éste no fuera sino una marca que señala la ruta más corta entre dos puntos alejados. Es un camino de penetración de la costa a la sierra, de carácter comercial y principalmente religioso. Debió servir para el intercambio de los productos marinos y serranos y para el comercio de sal; pero, sobre todo, debió ser la vía sagrada por donde traficaban los cuidadores y peregrinos de los templos erigidos en la costa y en la sierra a una misma divinidad o a una misma clase de divinidades.

La Muralla es una construcción reciente. Debe remontarse más allá del período incaico. 


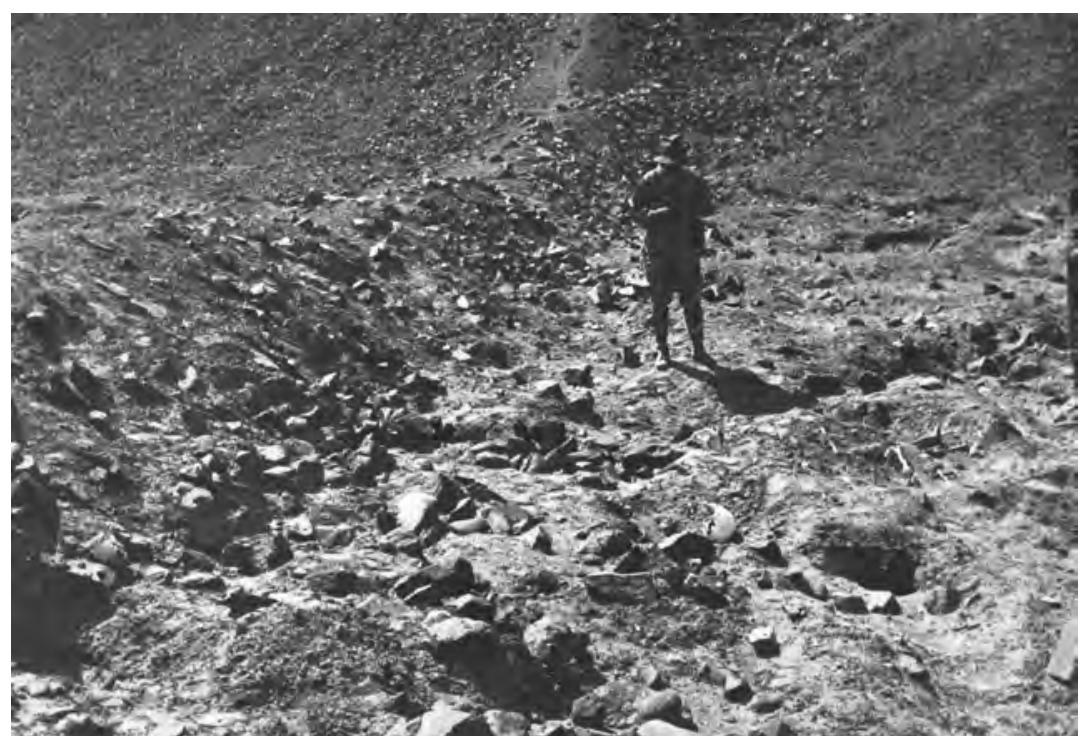

/ F4/12a/ El Dr. Tello junto a la Gran Muralla por el lugar donde ésta cruza un cementerio

Está construida en muchos sitios sobre cementeriosMuchikySub-Muchik,ChimúySub-Chimú, comprendidos dentrode losúltimoshorizontes de la prehistoria peruana. En ciertos lugares, tumbas recientes Sub-Chimú han sido halladas dentro de los escombros de la Muralla lo cual revela que los cementerios por donde cruza ésta continuaban usándoseaún después delaconquistaespañola.

No se podría determinar con exactitud qué nación construyó este monumento. Este acontecimiento debió tener lugar dos o tres siglos antes de la Conquista y en ella tomaron parte, seguramente, varias naciones coetáneas que usaban diversos tipos de alfarería bicroma y policroma que estuvieron incorporadas dentro de una vasta organización política sea Chimú, Huamachuco o Inka.

\section{Sobre la existencia de monumentos similares a éste en otros lugares del Perú}

La Muralla de Santa no es la única en el territorio del Perú. Existe en Huaura otra muralla importante entre el término de la hacienda Rondoy, por el Este, y el peñón de Chacaca, por el Oeste. Esta Muralla es el antiguo camino que, viniendo de la sierra, penetra al valle, atraviesa por la hacienda de Maso, y llega a Chacaca donde están las ruinas del antiguo Templo de Choke Ispana. En el valle de Supe he encontrado restos de otra muralla que parece partir del Templo de Chimú Kápac y avanzar hacia el interior. Algunos investigadores han creído que éste sea el camino de los incas. En el valle de Huarmey hay otra muralla que lo cruza de Norte a Sury asciende a las colinas alcanzando, por un lado, uno de los peñones contiguos a la ribera marina. Por la falda norte del gran peñón de Chiquitanta, en el valle de Chillón, aparece igualmente otro soberbio muro del mismo estilo que el de la Muralla de Huaura; asciende a la cumbre del peñón en la tierra cultivada para aparecer más tarde en los peñones que bordean elladonorte del valle.

También de la vieja ciudad del Lima, llamada Huática, de la misma ciudadela sagrada donde están los grandes templos llamados Waka Aramburú, Waka Concha y Waka La Campana, parte otra muralla en dirección NEy aparece en la margen derecha del río Rímac, en diversos sitios como Mango Marka y Cajamarquilla. La llamada Muralla de Circunvalación de Pachacamac posiblemente es también el término de otro camino, tal vez el de la gran vía que pasaba por Lomayacu, Mushiay Pariakaka.

A poca distancia del balneario de Pucusana existe también otra muralla semejante a la de Santa en sus porciones más bajas. Parte del pie del antiguo templo hoy llamado Cerro de la Bandurria; corre en dirección Norte sobre la cima de las colinas; se pierde en el llano desértico y reaparece al pie de los espolones occidentales de la Cordillera. 


\section{ANEXO*}

\section{De los cementerios encontrados}

De la choza de Waka Corral a Sarcope hay una legua y cuarto. En este trayecto el camino de herradura sigue casi paralelamente a la Muralla. A muy poca distancia de la choza se encuentra un pequeño cementerio sobre el cual pasa el muro. Está situado sobre una pequeña loma o montículo y contiene tumbas del tipo Muchik puro, sin mezcla de otros estilos. Sin embargo, los cadáveres están frescos. Además, abundan las palas de madera para excavar o de labranza; también hay muchos fragmentos de tazas campanuladas, sobre todo cántaros antropomorfos que representan hombres con un mono en la frente.

En la falda norte de este montículo, el joven Roosevelt encontró de modo casual, por haber pisado su caballo una olla grande muy quemada, el cadáver de una criatura como de 7 años. La olla, en la que se guardaba esos restos, estaba acuñada o protegida con piedras y fragmentos.

El hallazgo de Roosevelt me obligó a estudiar este cementerio. Se halla en la parte alta de los ranchos viejos de Waka Corral. Es grande y sobre la superficie se constatan hileras de adobes rectangulares y también algunas piedras. La posición de los cadáveres enterrados es horizontal; el cráneo parece deformado con aplastamiento occipital; el paladar está manchado de verde. La alfarería es muy abundante, tanto la fina como la utilitaria Muchik; hay muchos fragmentos de vasos grandes campanulados, restos de cabezas de alfarería con cerquillo y en las orejas tubos cilíndricos. También muchos restos de balanzas de mates, alfarería represen-

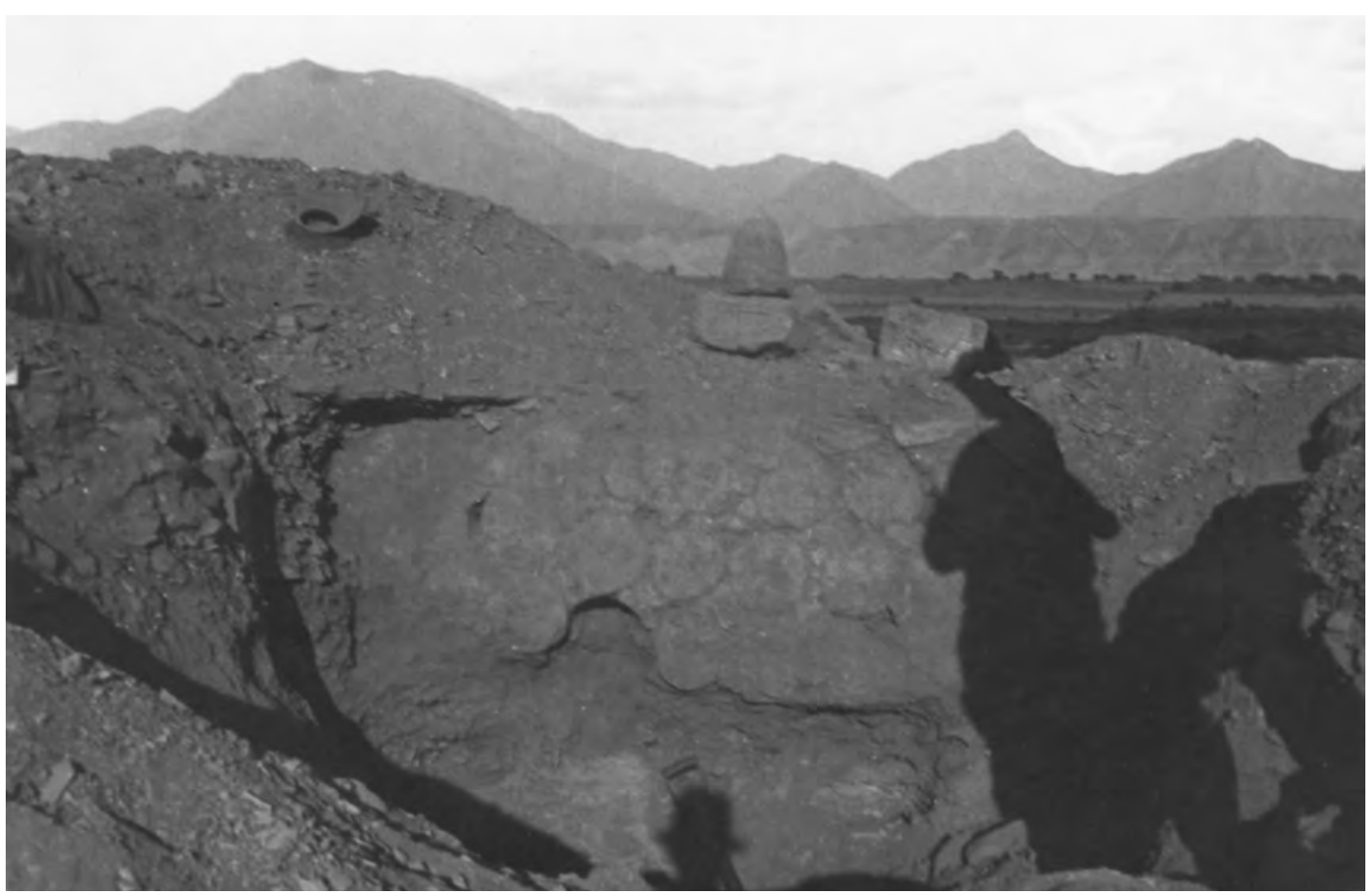

/F4/9a/ Capa profunda del cementerio que está junto a la Gran Muralla, cerca de Waka Corral. Nótese los ladrillos cónicos redondos

* Este anexo fue escrito por Jorge Crovetti, quien lo adjuntó en el informe que le presentó al Dr. Tello para que se incluyera en la versión final del texto sobre la Muralla de Santa. 
tando figuras humanas y, en general, gran variedad morfológica y figurativa de alfarería Muchik.

En el camino de Santa Clara a Waka Corral se pasa por cuatro cementerios: el primero, está cerca del canto del río en la culata de Waka Corral; el muro pasa a cierta distancia de este cementerio que es de tipo andino. El segundo cementerio, está en la quebrada del camino real y es el que anteriormente se ha descrito; en él se han encontrado tumbas explotadas y parece estar cubierto por los derrumbes del muro. Dentro de los terrenos de Waka Corral se encuentran los cementerios principales: uno (el tercero) está en la falda del cerro, al Este de la choza del yanacón Novoa. Este cementerio es grande y contiguo a la Muralla. La waka se llama Toma de Corral. El cementerio está muy explotado, encontrándose considerables cantidades de huesos humanos en la superficie. De las excavaciones que se hicieron se pudo encontrar tumbas del tipo Callejón, además muchos fragmentos de alfarería tipo Muchik con predominio de las tazas grandes campanuladas. Las tumbas son sistos construidos con piedra, no hay abobes. El muro pasa sobre este cementerio.

Avanzando un poco más hacia el oriente se encuentra el cuarto cementerio de Waka Corral. Aquí también el muro pasa por el propio cementerio que, como el anterior, está muy explotado. Las tumbas, vaciadas pero manteniendo todavía los productos encontrados en ellas, como huesos y fragmentos de cerámica, están situadas en el muro. Una de las tumbas tiene especial interés porque se halla en asociación con la Muralla misma. Está debajo de la base de la Muralla y ha sido excavada profundamente. Tiene en la actualidad $2.5 \mathrm{~m}$ de profundidad. La excavación permite cerciorarse de que el muro no tiene cimientos sino que las piedras han sido colocadas encima del suelo que ya guardaba cadáveres, como si al construirse la Muralla se hubiera ignorado la existencia de este cementerio. De la base del muro a la profundidad donde ha sido excavada la tumba hay de $3.8 \mathrm{~m}$ a $2 \mathrm{~m}$. Un poco más afuera de esta excavación se encuentra otra, tan amplia y profunda como la anterior, cuyo examen ofrece datos muy ilustrativos. Se trata de un pozo grande, de $3.3 \mathrm{~m}$ de profundidad. El diámetro del pozo, cerca de la boca, es de $4 \mathrm{~m}$ en dirección $\mathrm{N}$ - S y es un poco más largo en dirección E - O. A juzgar por las capas de las paredes de la excavación, ésta ha cortado primero una capa de tierra suelta; después un muro formado por varias hileras de abobes odontiformes dispuestos en tres o cuatro hileras apilonadas y alternando entre sí. En la capa de tierra suelta aparecen además dos hileras de adobes rectangulares cuyas caras presentan surcos que no son sino huellas del molde de cañas que debió ser usado para su fabricación. Esta capa de tierra y adobes rectangulares tiene como $1.20 \mathrm{~m}$ de espesor y corresponde, seguramente, a las tumbas de la capa superficial. Este mismo tipo de adobes aparece en las paredes de otras tumbas abiertas contiguas a ésta y que también contienen multitud de fragmentos de cerámica Muchik dejada por los huaqueros.

Los cementerios hasta ahora descritos se hayan, en su mayor parte, sobre pequeñas terrazas o lomas bajas casi al pie de la falda de los cerros que bordean el valle por el Norte o bien en alguna hoyada. Todos ellos han sido violados por los huaqueros. La Muralla pasa siempre a muy poca distancia de estos cementerios, y en la mayoría de las veces por encima de ellos. Casi todas las tumbas abiertas presentan huellas frescas de excavación y abundan en la superficie restos de esqueletos humanos y alfarería correspondiente a diversos estilos. Así, se encuentran corrientemente ollitas quemadas con ornamentos en relieve, tazas campanuladas, alfarería ceremonial Muchik, alfarería negra Chimú, etc. No se halla hasta ahora resto alguno de alfarería propiamente andina de Santa.

De Sarcope a Tanguchi hay aproximadamente dos leguas. Dentro de los límites de Sarcope se encuentra el gran cementerio de El Cenicero que se halla al pie de un cerro muy elevado, el cual tiene muros y terrazas alrededor y que probablemente es una waka o templo. Este cerro 


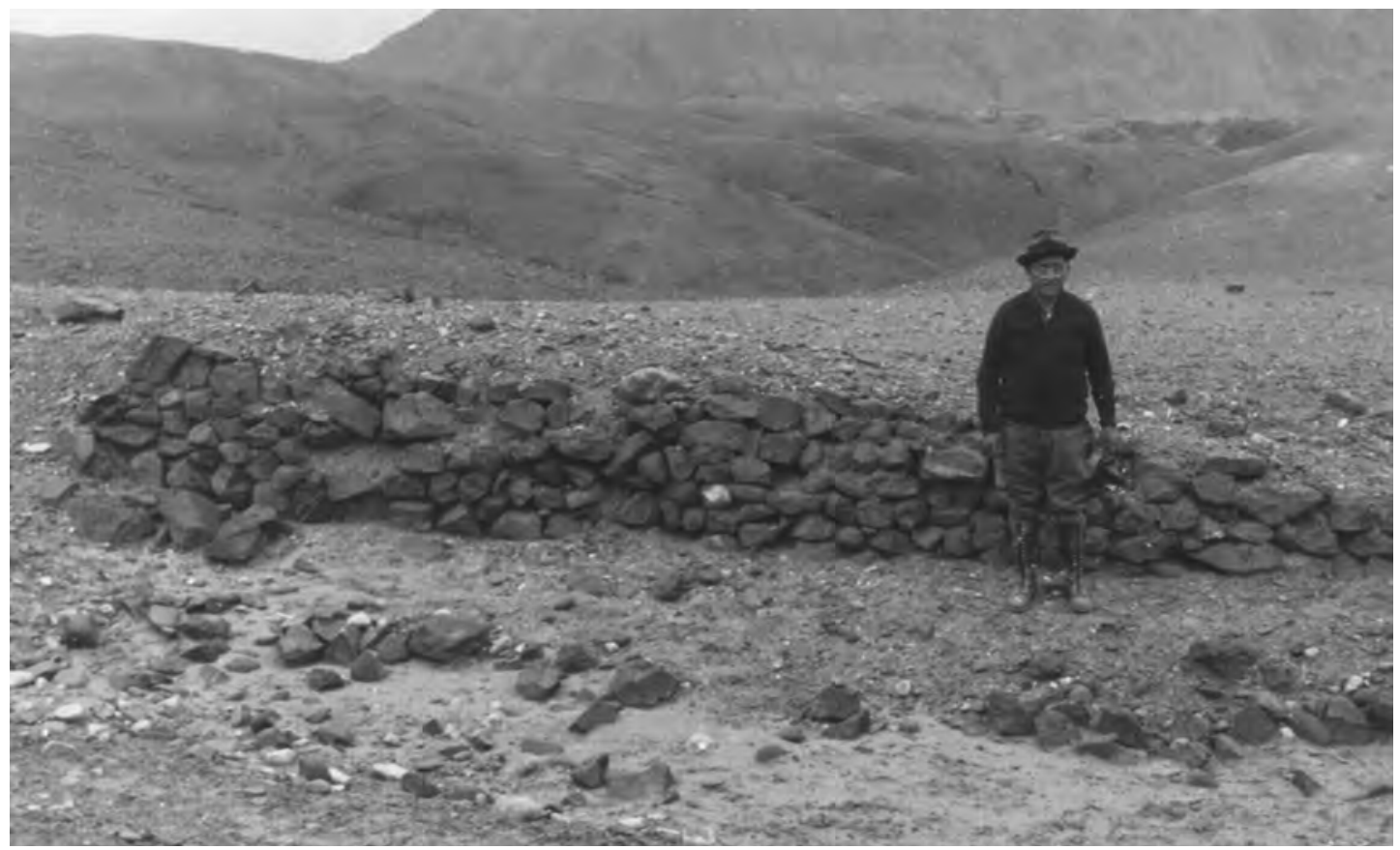

/F4/9d/ El Dr. Tello junto a una porción de la Gran Muralla, mostrando el tipo de construcción. Santa Clara.

llamado El Castillo se ve bien desde El Cenicero y las murallas que lo circundan son de piedra y barro. Hace algunos años, un individuo de Sarcope trabajaba este lugar en la creencia de que allí existía algún entierro.

El cementerio de El Cenicero es muy extenso. Está dividido en cuarteles por medio de muros a manera de terrazas o muros de contención. Uno de éstos -el principal- divide, por decirlo así, al cementerio en dos grandes proporciones: una superior y otra inferior. En el cuartel inferior hay abundante tierra amontonada y el superior es cascajoso y está sembrado por todas partes de fragmentos de cerámica. En rigor, el cementerio está en un enorme basural que por los restos de alfarería que presenta hace la impresión de una "fábrica de alfarería". Las tumbas en la parte superior del cementerio son relativamente pequeñas, los cadáveres frescos, y la alfarería de tipos muy mezclados, aunque con predominio de los tipos utilitarios. En la parte inferior, los pozos son grandes y profundos; los cráneos no tan frescos como los del cementerio superior; la alfarería es muy abundante y con predominio de la ceremonial Muchik, pero siempre asociada con las formas utilitarias, y también con vasijas negras con ornamento y vasijas con ornamentaciones en relieve de tipo andino. Llama la atención la falta de deformación de los cráneos recogidos en la parte baja del cementerio.

Cerca del camino de herradura que pasa a través de este gran basural, en dirección $\mathrm{S}-\mathrm{N}$, he examinado una tumba grande. Las paredes han sido formadas con piedras pequeñas pircadas y en la parte superior con varias hileras de adobes rectangulares. Dentro de la tumba y en los contornos he encontrado trozos grandes de alfarería ceremonial Muchik y un cadáver relativamente fresco.

Este gran basural presenta hoy una enorme facilidad para su estudio porque las lluvias del año 1925 lo han cortado, produciendo zanjas profundas que hoy permiten ver claramente los detalles estructurales de este terreno y, principalmente, conocer el monto y las variaciones de 
estilo de las enormes masas de alfarería rotas que se hallan dentro de estos basurales. En ciertos sitios las zanjas tienen $5 \mathrm{~m}$ de profundidad, y la basura en ambos lados de la zanja es más o menos uniforme: tierra negruzca mezclada con arena, de aspecto de humus, fragmentos de sogas, telas rústicas de algodón, cañas, corontas de maíz, frejoles, y trozos de alfarería casi en su totalidad rústica o quemada. Llama la atención la escasez de alfarería ceremonial Muchik en la basura, y la frecuencia con que aparece esta alfarería mezclada con Chimú en las tumbas abiertas en este basural. Entre los fragmentos colectados por mí en el recorrido que hice de este extenso cementerio, figuran los siguientes tipos (apreciados sólo por sus fragmentos):

1-. Cántaros semi antropomorfos: el gollete transformado en una cabeza humana y las manos en relieve sobre la panza del cántaro. Este tipo es uno de los más frecuentes, y aquí aparecen sus más típicas representaciones (en la cabeza un gorro).

2-. Grandes tazas campanuladas y de tamaño medio y pequeño: las de tamaño medio y pequeño sin pedestal, bañado en rojo y con dibujos simples trazados con líneas gruesas y blancas.

3-. Cántaros de diferentes tamaños cuyo gollete (y sólo el gollete) está transformado en una cabeza humana escultórica bien moldeada.

4-. Cántaros globulares del tipo más fino ceremonial Muchik con gollete tubular arqueado. Estos tipos son los únicos que aparecen hacia la parte oriental del cementerio y hacia la occidental es donde ya aparecen los otros tipos, o sea, los muy ordinarios Muchik y los Chimú.

Las informaciones dadas por los huaqueros coinciden con los siguientes hechos: 1.- Que no hay tipo único de tumbas; tampoco hay costumbre uniforme de enterrar los cadáveres. 2.- Las tumbas pueden ser simples hoyos abiertos en el terreno cascajoso natural cubiertos con basura y pueden ser hoyos abiertos dentro de la misma masa de basura, con paredes de piedras pircadas; o bien pueden ser hoyos rectangulares con adobes igualmente rectangulares. 3.- El cadáver aparece por lo general echado, en algunos casos sentado y enfardelado y, en casos excepcionales, parado. 4.- El cadáver está envuelto en telas rústicas de algodón y algunas veces tiene útiles de costura o de tejidos, objetos de cobre y en algunos casos telas de diferentes colores. 5.- En cada tumba se encuentra, por lo general, cuatro o cinco piezas de alfarería, unas ceremoniales y otras ordinarias o comunes; no es raro encontrar piezas finas Muchik con cántaros comunes negros Chimú.

\section{Fábrica de alfarería muchik}

$\mathrm{Al}$ recorrer El Cenicero, lo que más llama la atención es la gran abundancia de alfarería Muchik y el predominio en ella de sus tipos utilitario y ceremonial. En la parte interior del cementerio se encuentra alfarería mezclada y se recogen varios fragmentos de ejemplares que corresponden a cántaros globulares algo cónicos, con asitas auriculares en el hombro y el gollete transformado en cabeza humana en su mitad inferior, y en la superior libre, pero que hace la impresión de un gorro; éste es todo hecho en barro negro. Este tipo de alfarería no es ni Muchik, ni Chimú; posiblemente es una forma correspondiente a algún otro tipo ignorado. Además, en esta parte del cementerio he recogido grandes fragmentos de alfarería muy gruesa, que en la cara interna presenta surcos gruesos y profundos; alfarería que he encontrado también en los basurales que se hallaban al oriente del pueblo de Chimbote y en Lacramarca y en algunas Wakas de Chincha y Pisco.

En la parte baja del cementerio he hallado una considerable cantidad de fragmentos de trompetas, muchos pedazos de cuchimilcos y cántaros con ornamentaciones en relieve. No he encontrado por ninguna parte huellas manifiestas de construcciones que correspondan a antiguas habitaciones. Es posible que hayan existido chozas, dentro o fuera del área del cementerio. No se explica donde ha vivido la gente que ha fabricado tanta cantidad de alfarería y que ha dejado tan gruesas y extensas capas de basura. 


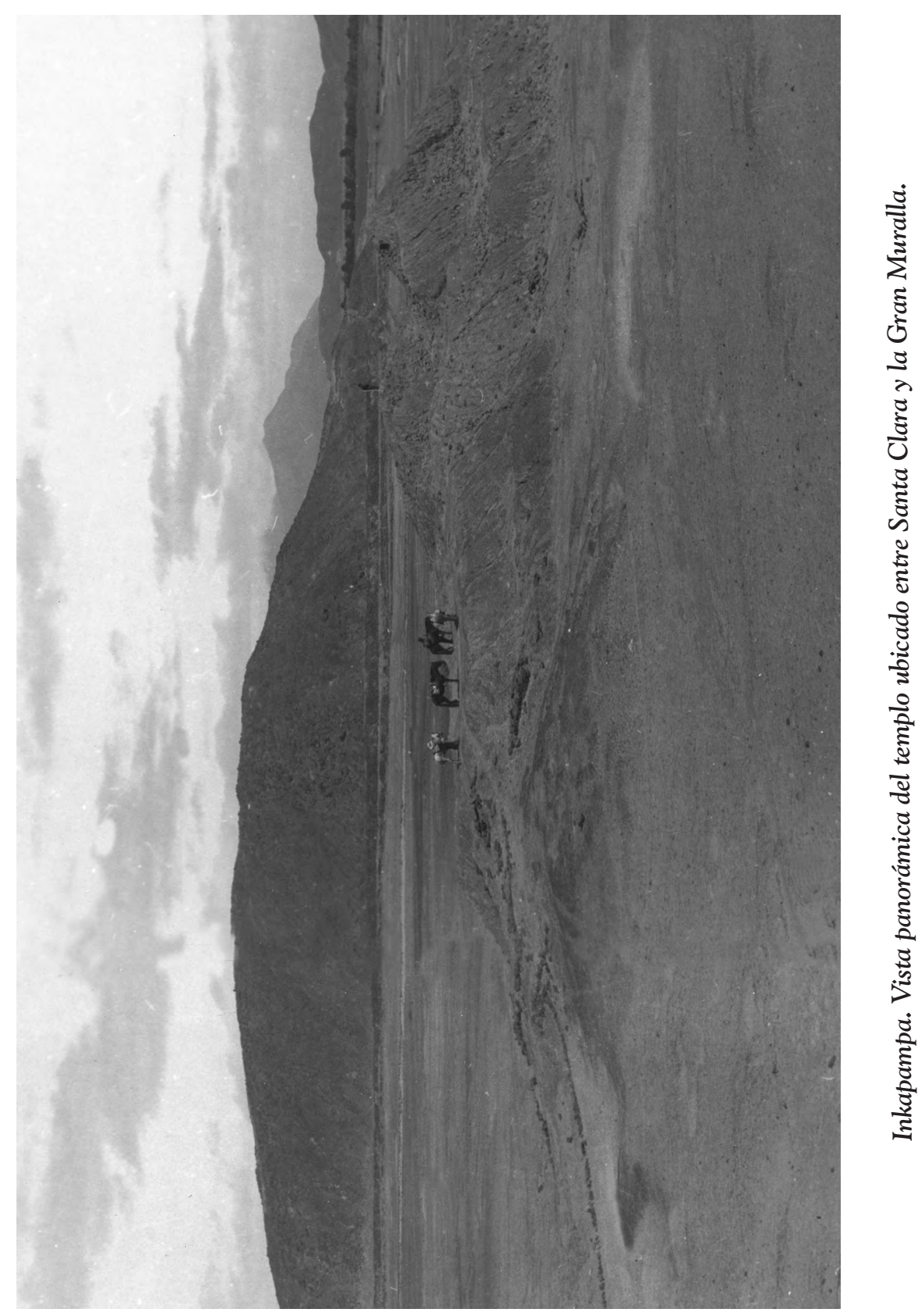




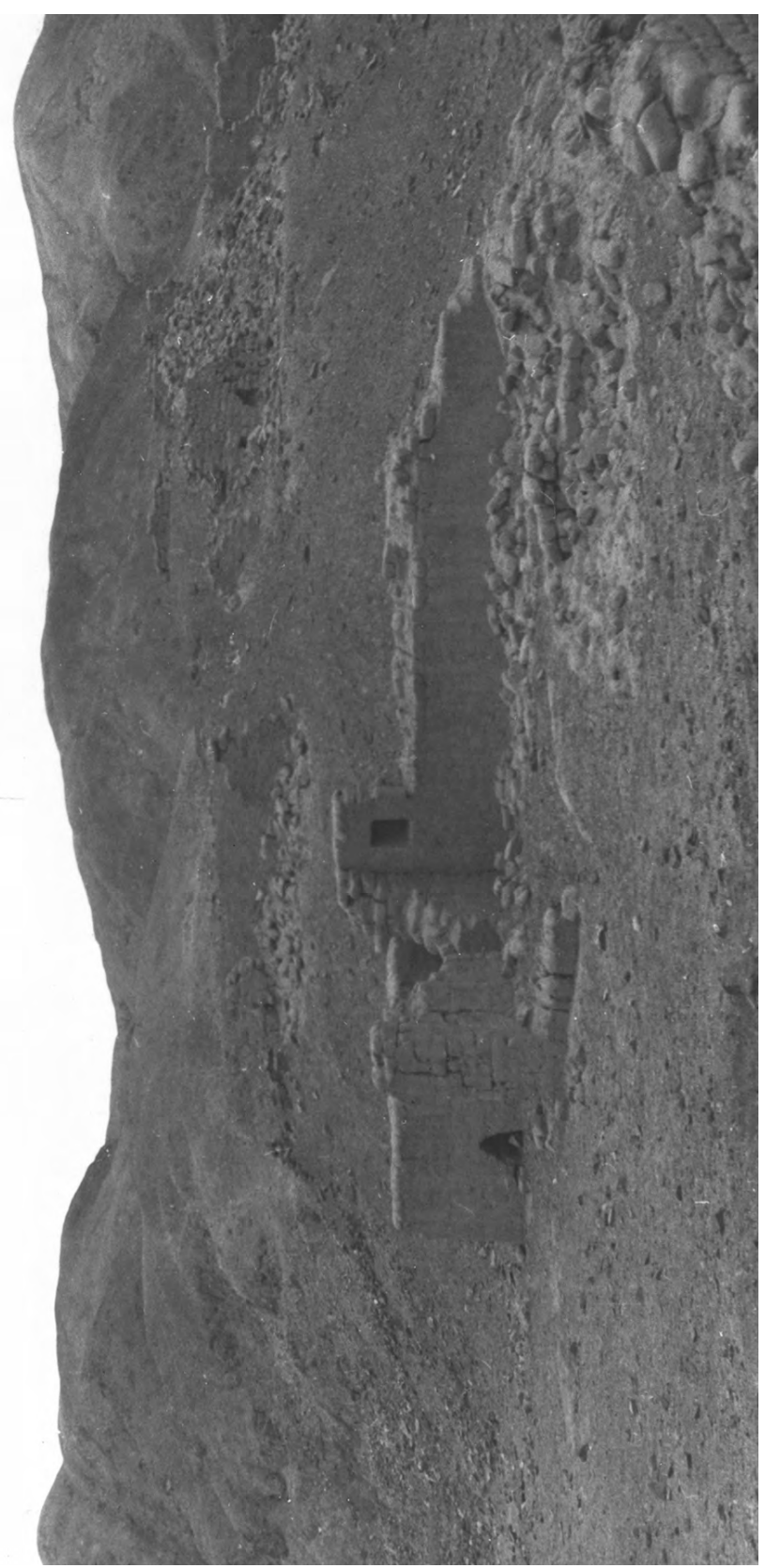

